\title{
Design and Simulation Study of Small Four Wheel Vehicle Chassis for Single Driver
}

\author{
M. Z. A Rashid ${ }^{1}$, M. F. Abdul Latif ${ }^{2}$, M. Nur Othman ${ }^{2} \&$ Marizan Sulaiman $^{1}$ \\ ${ }^{1}$ Faculty of Electrical Engineering, Universiti Teknikal Malaysia Melaka, Hang Tuah Jaya, Durian Tunggal, \\ Melaka, Malaysia \\ ${ }^{2}$ Fakulti Teknologi Kejuruteraan (FTK), Kampus Teknologi, Universiti Teknikal Malaysia Melaka, Hang Tuah \\ Jaya, Durian Tunggal, Melaka, Malaysia \\ Correspondence: M. Z. A Rashid, Faculty of Electrical Engineering, Universiti Teknikal Malaysia Melaka, \\ Hang Tuah Jaya, 76100, Durian Tunggal, Melaka, Malaysia. E-mail: \\ zamzuri@utem.edu.my/faruq@utem.edu.my
}

Received: September 25, $2014 \quad$ Accepted: November 10, $2014 \quad$ Online Published: August 30, 2015

doi:10.5539/mas.v9n9p240 URL: http://dx.doi.org/10.5539/mas.v9n9p240

The research is financed by Universiti Teknikal Malaysia Melaka (UTeM) under short term grant no. PJP/2014/FTK(20C)/S01355.

\begin{abstract}
This paper highlights the development and vibration analysis of a four wheel vehicle chassis for single driver. A chassis is developed and proved to have a strong structure and minimized vibration. First, this project is concentrating on determining the static stress and strain concentrated on the chassis structure as well as determining the resultant displacement of the chassis frame with applied load exerted on the chassis. This is vital because the chassis acts as the main frame of the vehicle that subjected to stress, strain and vibration during the vehicle moves. Second, this project is also focussing on the developing a chassis structure for a four wheel vehicle for single driver system with a minimum vibration since vibration could cause the efficiency and the performance of a vehicle to drop. In this paper, the results obtained from the static test conducted on the basic chassis frame structure designed by using Solidworks software are presented as well as the fabricated basic chassis frame structure. The three dimensional modelling chassis frame structure is designed using Solidworks software and the static test is conducted in the simulation environment of the Solidworks software as well. The fabrication of the basic chassis frame structure is fabricated using the selected material which is the $25 \mathrm{~mm} x$ $25 \mathrm{~mm}$ square mild steel tube with the thickness of $1.6 \mathrm{~mm}$ and the method of welding is used in developing the chassis. The developed chassis frame structure is able to withstand the applied load with a satisfactory factor of safety (FOS). The chassis structure will further modified and improved into a integrated chassis structure combining with engine, wheels, brakes, motor and steering system.
\end{abstract}

Keywords: chassis, single driver, vibration, solidwork simulation

\section{Introduction}

Chassis acts as the main frame of the body structure of the vehicle. It is one of the most important part to be considered when designing a vehicle. Chassis is defined as the lower part of a vehicle which includes the wheels, frame, driveline, engine and suspensions. There are three types of chassis structure which is the ladder chassis frame, space frame chassis and monocoque chassis.

Elements that always been considered during the design of the chassis structure is such as the strength and the stiffness of the chassis. Chassis built for vehicle has to be strong because it tends to be subjected to static stress, strain and also vibration due to various dynamic excitation. Static analysis of the chassis structure is important in determining the safety of the chassis structure. Besides that, vibration on the chassis can affect the comfort during ride, the stability of the whole vehicle as well as the safety of the vehicle. Besides that, vibration can also caused high stress concentration at certain part of the structure, fatigue on the structure and loose in the joints of the structure. Therefore, the vibration analysis is vital to be done on the chassis, ensuring the safety and the stability of the vehicle. 
This project is about developing a four wheel vehicle chassis for single driver as well as performing vibration analysis and static analysis on the chassis developed. The design of the chassis will utilize the space frame chassis type and the material chosen is $25 \mathrm{~mm} \times 25 \mathrm{~mm}$ square mild steel tube with the thickness of $1.6 \mathrm{~mm}$. The square mild steel tube is cut into desired and welded using $2.5 \mathrm{~mm}$ thickness welding rod to form the space frame chassis.

Before the process of developing the chassis been started, a three dimensional modeling of the chassis is drawn using Solidworks software in order to perform finite element analysis on the designed chassis structure. Materials used in constructing the whole chassis structure is also been identified and assigned in the software to increase the accuracy of the result. Static analysis is done on the modeling of the chassis using the simulation functions in Solidworks software to determine the distribution of static stress on the structure and the displacement of the structure after the load force is added into the simulation. The safety factor for the chassis can also be calculated after the analysis. The objectives of this project are stated as follows;(i)To develop a chassis structure with reduced vibration.(ii)To identify and analyze static stress, strain and the vibration on the chassis designed

\section{Motivation}

Chassis of the vehicles is the frame work that are used to support the body and all the parts of a vehicle. Chassis played a vital role in vehicles for example cars, trucks, SUV, sports car and also racing car. The design of the chassis of the vehicle has different kind of structure. For instance, the honeycomb sandwich panel monocoque chassis, the ladder chassis frame and the tube space frame structure. In this project. A chassis structure need to be produced that could minimize the vibration as well as having a stable and strong structure.

There are researchers in (S.Chignola et al., 2002) stated that the design of the chassis is combining the factors of performance and safety. Performance which is the torsion stiffness of the chassis that directly affects the cornering behavior of the vehicle. Safety of the chassis design is also determined by the absorbing capabilities of the structure. In manufacturing the low cost vehicle chassis using the low-carbon steel tubes, steel tubes are cut and welded to form the structure of the chassis. This method of fabrication is stated as the technologies used in the late fifties and the early sixties. Apart from that, the usage of aluminium in vehicle design could reduce the weight of the vehicle while maintaining the performance and safety of the vehicle. (Hirsch,2011) pointed out the full usage of aluminium on the car body could reduce the weight of the body approximately $30-40 \%$. Aluminium solutions were already established in AUDI A8 cars by having aluminium chassis, power train, bumpers and car body.

Based on (J.Reimpell et al., 2001), the important variables in vehicle engineering includes the vehicle centre of gravity, body (sprung-mass) centre of gravity and also axle (unsprung mass) centre of gravity. The distance of vehicle centre of gravity and the distance of body centre of gravity from the front or rear axle as well as the height above the ground are crucial for; (i)Braking and acceleration capability, (ii) Determining climbing ability, (iii) Designing brake system, (iv) Designing body centre of gravity and aspects of vibration stability,(v) Driving stability,(vi) Determining mass moment of inertia.They also stated that low centre of gravity could also contributed in fewer driving dynamic problems and increased the performance of the vehicle(J.Reimpell et al., 2001).

Moreover, the torsional stiffness of a vehicle is an important element in producing a safe vehicle. When the vehicle is in motion and steering force is exerted on the chassis, the chassis will experience twist stress. Therefore, the studies on vehicle torsional stiffness has to be done to ensure the vehicle handling performance. In (S.Y.Pang et al., 2001), it is stated that chassis of a vehicle has 2 roll degree of freedoms, roll angle and roll angular velocity of sprung mass centre. The torsional stiffness of the vehicle could affect the roll angle of the vehicle after a analysis on the chassis to determine the influence of torsional stiffness on the roll angle at the suspension of the vehicle Based on the reviewed researches, there are few characteristics of a chassis of a vehicle need which is the strong structure, using light but strong material, could withstand several types of stress and vibration. Besides it also able to withstand a range of applied load and the importance of torsional stiffness on chassis design.

Furthermore, for every chassis designed, several tests will be done on the chassis in order to justify the functionality of the chassis. For example, dynamic analysis is the one of the common test done on the chassis design.Authors in (R.Rajappan \& M.Vivekanandhan, 2013), stated that when a vehicle travels along the road, the chassis of the vehicle is excited by the dynamic force caused by external issue such as the road condition and also internal issue such as engine and transmission. Based on the analysis done by (R.Rajappan \& M.Vivekanandhan, 2013), the result is based on the first 30 frequency modes. The chassis maximum 
displacement in $\mathrm{x}, \mathrm{y}$ and $\mathrm{z}$ direction is determined as well as the natural frequencies from the modal analysis. There are groups of researchers performed analysis on their designed chassis using Modal Analysis in ANSYS software after modeling of the 3 dimensional chassis design is completed (R.Rajappan \& M.Vivekanandhan, 2013), (Y.S.Rajput, et al., 2013), (G.Solasa et al., 2013), (M. Z. A. Rashid et al., 2012), (The dynamic analysis is done to determine whether the natural frequency of the chassis is in the suitable range.

Moreover, (Y.S.Rajput, et al., 2013) performed vibration analysis on a vehicle frame and stated that the natural frequency of the structure coincides with the frequency from forced vibration can caused resonance which could leads to failure to the structure. Besides that, the analysis done by (G.Solasa et al., 2013) is to determine the frequency in different mode. During the analysis, a few assumptions had to be made such as damping is ignored and any applied load is ignored. In the result, the natural frequency in each mode is determined. From an analysis done in China, the experimental modal was the chassis of a Land-wind X6. During the analysis, the system is supported by 2 plat tires, a 16-channel data acquisition system, a data analysis system, 16 accelerometer that act as sensors and a input hammer. 48 different points at the chassis are determined as the test points of the analysis and the points are selected mostly at the front or rear of the chassis. The analysis successfully outcome the frequency response of the chassis (W.L.Wang et al., 2010).

\section{Methodology}

The project methology in this project is divided into two parts which is the static analysis using simulation in Solidworks software and vibration analysis using sensors and programming codes. However, the first part of methodology is covered in this paper.

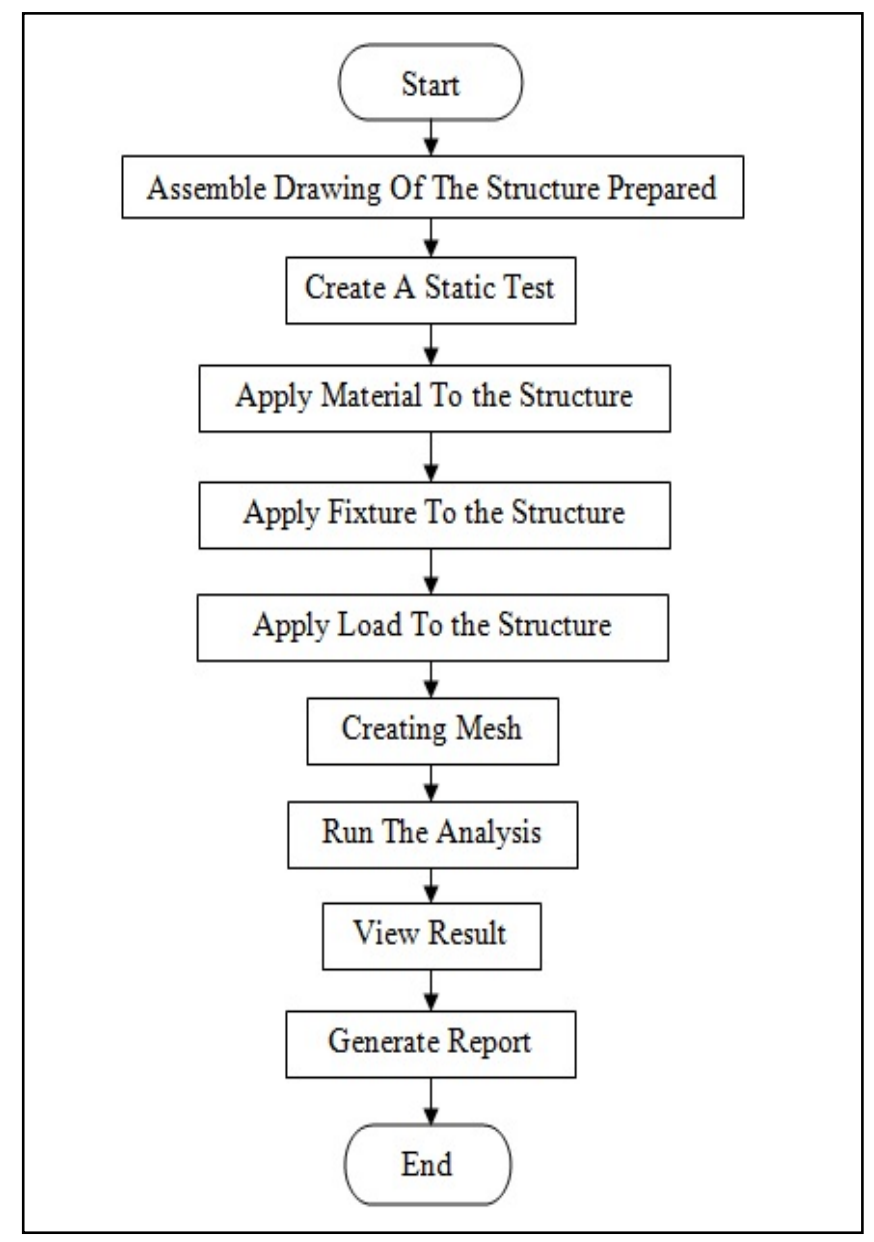

Figure 1. Flow chart of static test using Solidworks

The flow chart shown in Figure 1 illustrates the process flow of conducting the static test on the chassis design in Solidworks software. Initially, the assembled drawing of the chassis designed is prepared by connecting all the parts included in the chassis design. Then, the static test function is selected in order to start the experiment on 
the chassis structure. After that, the material of the chassis is chosen from the list provided in the database of the Solidworks software. Some specifications of the materials can be edited and need to be edited if the material used having different specifications. Then, the fixtures for the chassis is applied. Fixtures that available in the software are such as fixed geometry, fixed hinge and roller/slider. Then, the load is applied to the chassis structure. The value of the load is based on the total chassis weight and driver's weight, multiplied by the desired factor of safety. After that, mesh is created. Meshing is a process of splitting the geometry of the design into small and simple shaped called finite elements. The finer the elements will increase the accuracy of the data obtained from the experiment. After the meshing is done, the test is started and the result for the test is obtained. There is a function of creating a report from Solidworks software, therefore a report for the test is generated.

\section{Material Selection}

The material selected for this project are segmented into three parts; (i) Material For Chassis Structure, (ii) Material For Connecting Joint Of Chassis Structure and (iii) Material For Joining With Other Parts.

\subsection{Material for Chassis Structure}

The material chosen as the material in developing the chassis for the racing can is the $25 \mathrm{~mm} \times 25 \mathrm{~mm}$ mild steel square tube with the thickness of $1.6 \mathrm{~mm}$. The reason of choosing this type of material is due to the availability of the material and the low price of the material. The $25 \mathrm{~mm}$ x $25 \mathrm{~mm}$ mild steel square tube with the thickness of $1.6 \mathrm{~mm}$ is preferable compared to aluminium due to the ease of joining using welding method. Mild steel is easier to be welded compared to aluminium although the weight of the aluminium is lighter.

\subsection{Material for Connecting Joint of Chassis Structure}

Material chosen for connecting the mild steel square tube is the welding rod with the thickness of $2.5 \mathrm{~mm}$. The welding rod is chosen because welding method has the strongest connection in connecting mild steel compared to bolt or rivet. Since the chassis of the four wheel vehicle for single driver has to be very strong, therefore welding rod for welding is chosen.

\subsection{Material for Joining With Other Parts}

In joining the front nose and rear wing of this vehicle, the material chosen to join that particular parts is the mild steel bolt and nut. The bolts that have the standard of M6 is chosen to join the parts onto the chassis body. The reason of choosing bolt and nut because the front nose and rear wing of the go-kart need to be removed when not in use. Besides that, the bolt and nut are capable in withstand the weight of the parts.

For fixing the engine and motor in place at the chassis, mild steel bolt and nut of M10 are used. The M10 bolt and nut have the higher strength compared to M6 due to the thickness of the structure. The M10 bolt and nut are chosen due to the ease of dismantling from the chassis structure during maintenance work as well as having strong connection.

\section{Design}

This section will describe the design of the vehicle chassis for this paper. Table 1 summarize the specification of the chassis design set in this project while Figure 2 shows the three dimensional drawing of basic chassis structure.The drawing indicates that the location for joining front nose, the cockpit and location where rear wing will be connected.

Table 1. Specification of the chassis design

\begin{tabular}{ll}
\hline Item & Specification \\
\hline No of Seat & 1 \\
Track Width & Min 500mm (midpoint of tyre) \\
Overall height & Max 900mm from ground \\
Overall width & Max 1300mm \\
Wheelbase & Min $1000 \mathrm{~mm}$ \\
Overall length & Max 3500mm \\
Ground Clearance & Min 50mm with driver onboard \\
Bodywork width & Less than overall width \\
Weight & Max 140kg without driver \\
Cockpit & At least 50mm in front of \\
& steering wheel \\
\hline
\end{tabular}




\begin{tabular}{ll}
\hline Wheel & $300-325 \mathrm{~mm}$ \\
Wheel width & Min 100mm, max 163mm \\
Fuel & Unleaded RON 95/97 \\
No.of Wheel & 4 \\
\hline
\end{tabular}

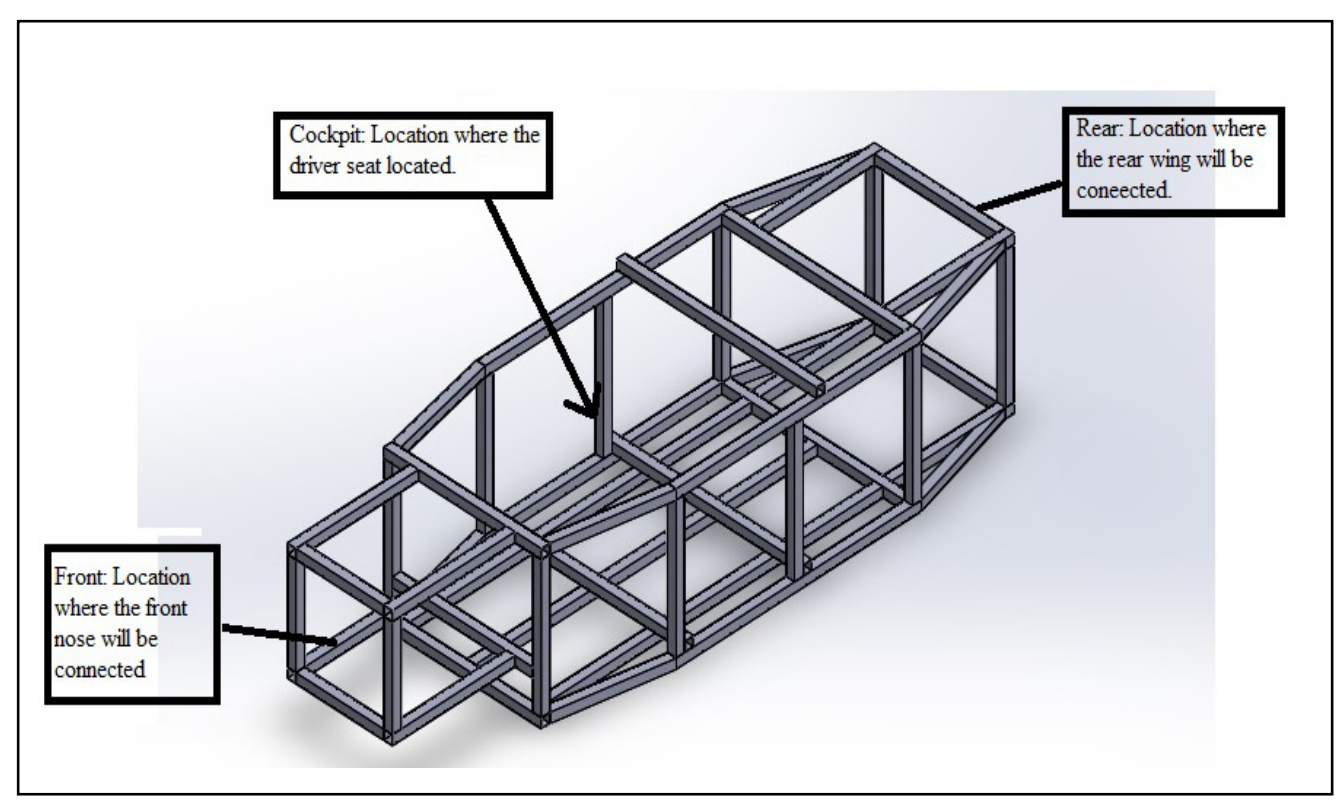

Figure 2. Three dimensional drawing of basic chassis

Figure 3 and Figure 4 show detail of the basic chassis drawing includes the dimension of the joining part for the front nose, the cockpit dimension, the dimension of the joining part of the rear wing and also the overall chassis structure dimension.

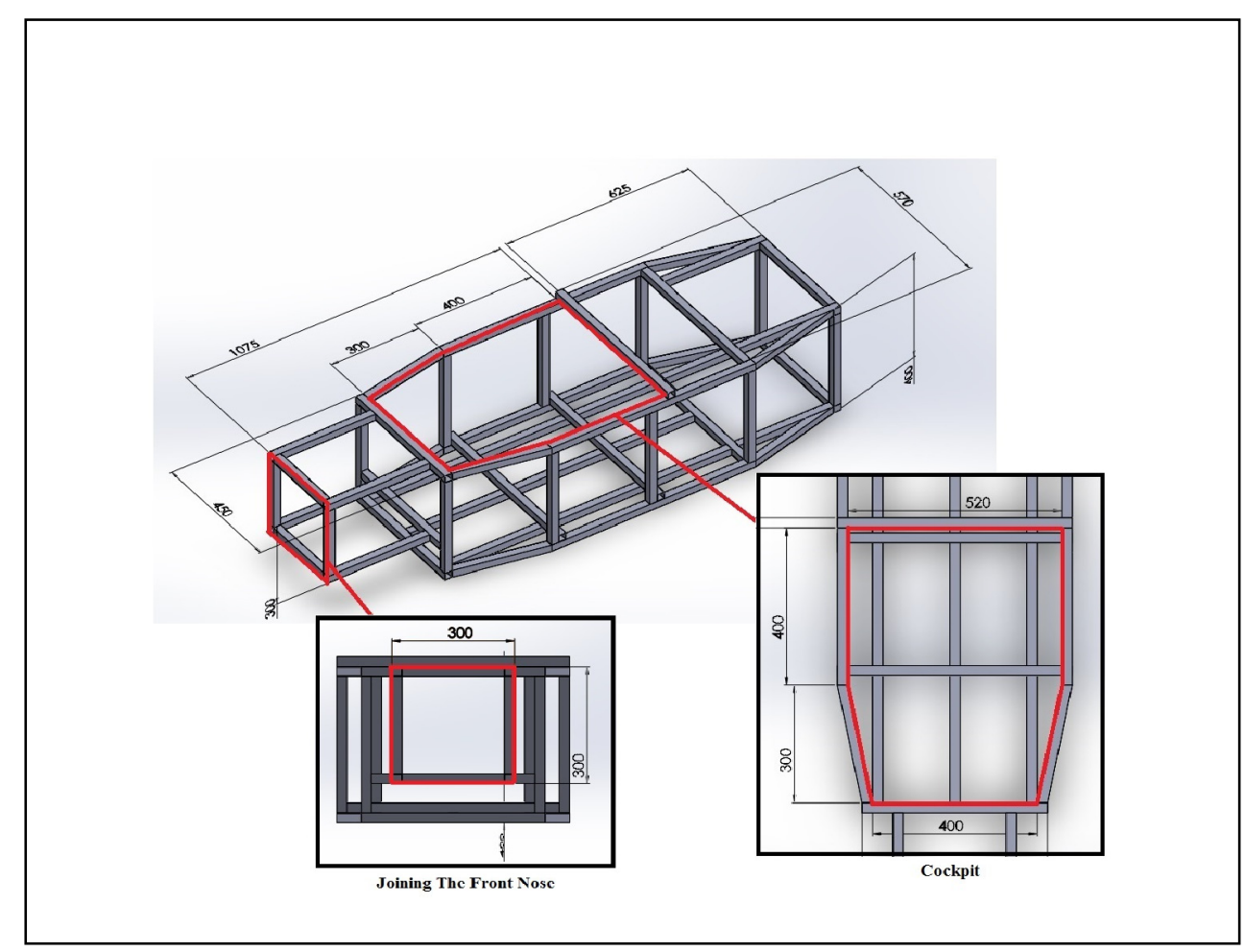

Figure 3. Dimension of the joining part of the front nose and cockpit 


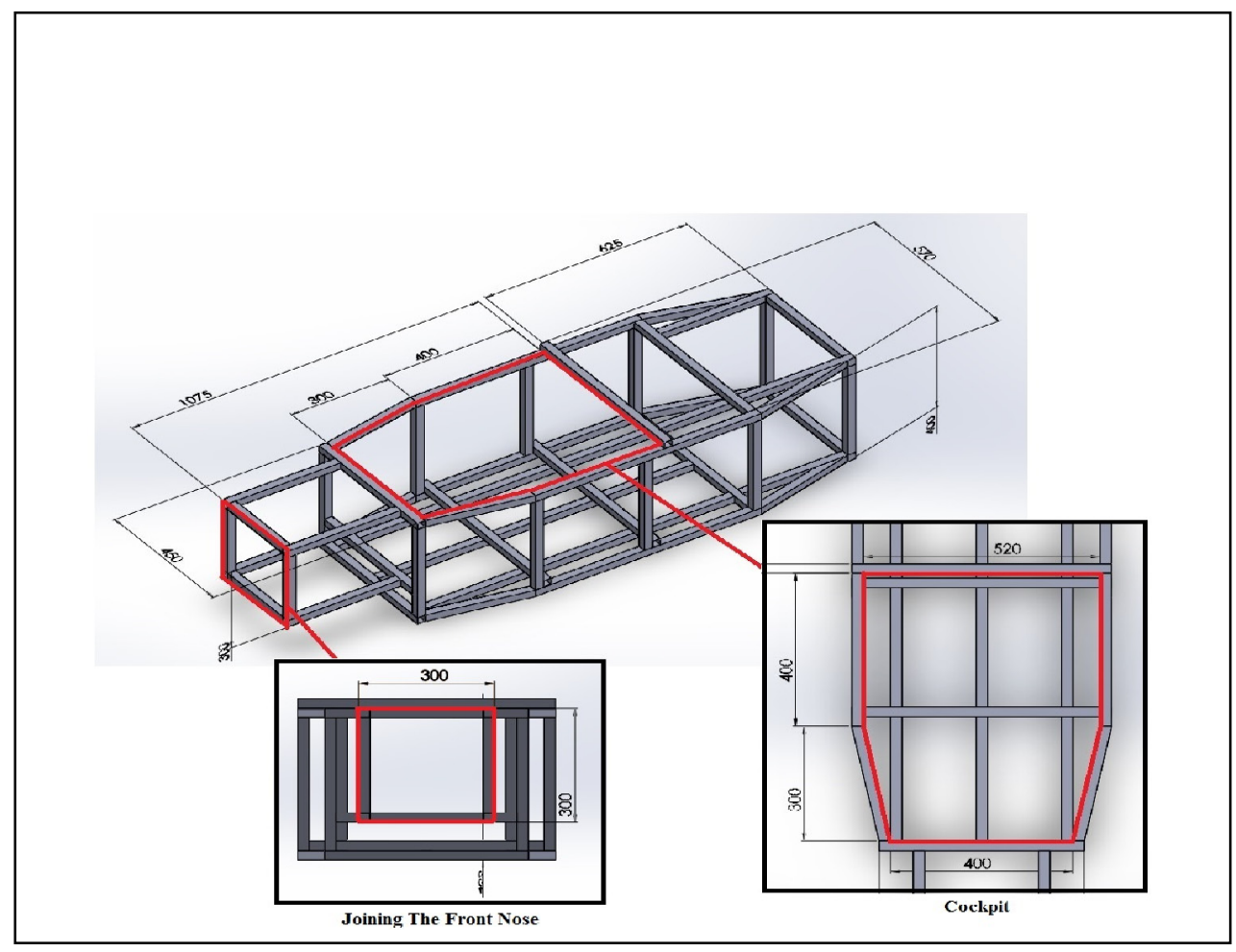

Figure 4. Dimension of the joining part of the rear wing 


\section{Result and Discussion}

In order to perform static test on the chassis structure, the fixtures have to be defined to determine how the structure is supported while the load applied to the structure is at $5000 \mathrm{~N}$ which is about 2.5 times the maximum weight of $140 \mathrm{~kg}$ chassis and the assumption weight of $60 \mathrm{~kg}$ of the driver. The fixture is fixed at the front and the rear part of the structure. The type of fixture chosen is the fixed geometry while the applied load of $5000 \mathrm{~N}$ which equal to a $5000 \mathrm{~N}$ normal force acting on the place where the driver is seated and the engine is located.

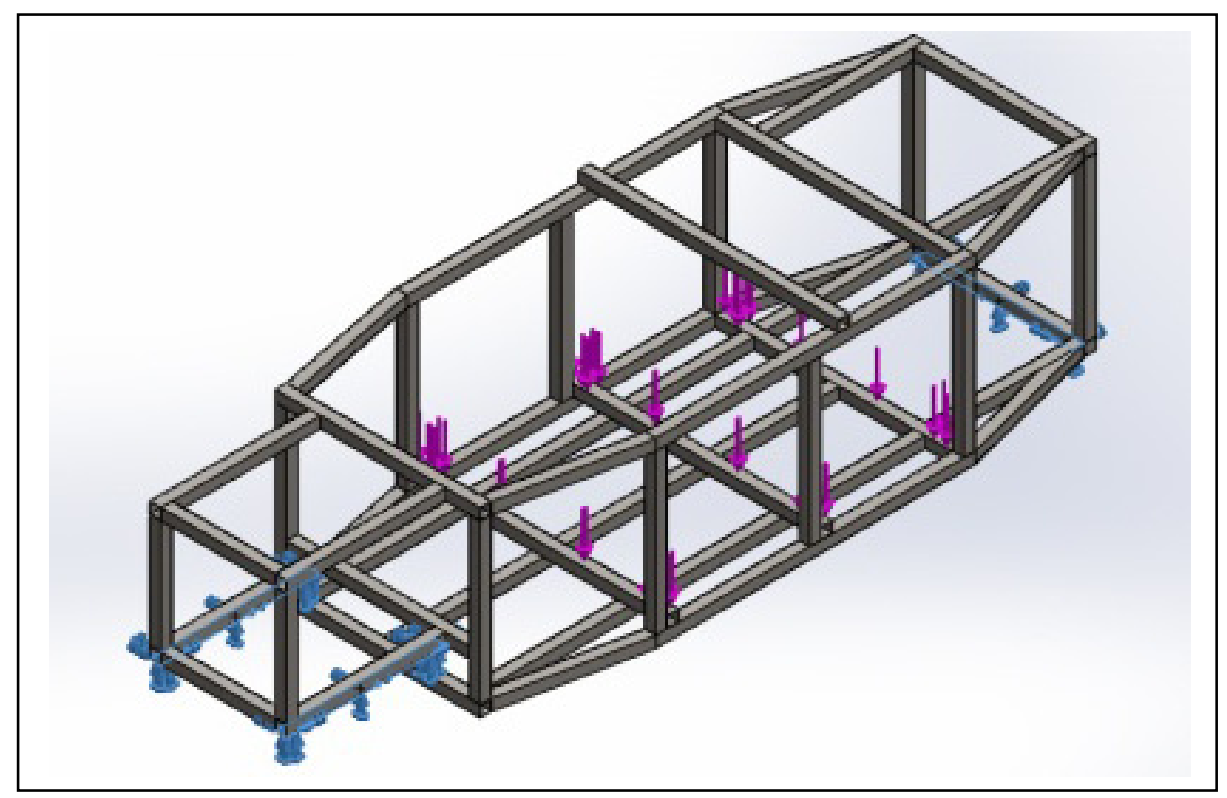

Figure 5. Three dimensional drawing of basic chassis

The fixture image indicated by using the blue colour arrows is shown in the Figure 5 while the load image illustrated by using the blue colour arrows is shown in the Figure 6 .

Then, after meshing is done on the chassis design, the structure of the chassis is shown in the Figure 7. The mesh detailed diagram is shown in Figure 8.

Another Figures, Figure 9 shows the Von Mises Stress result and Figure 10 shows result for resultant displacement.

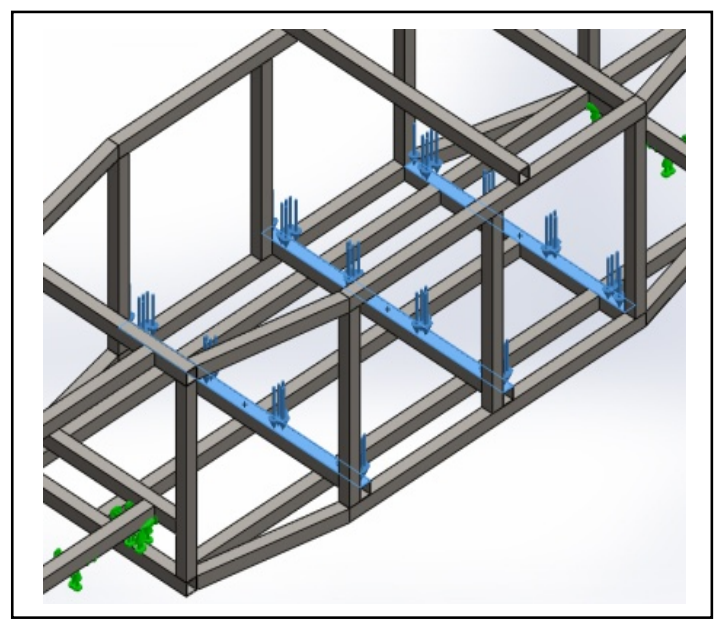

Figure 6. Fixture View 


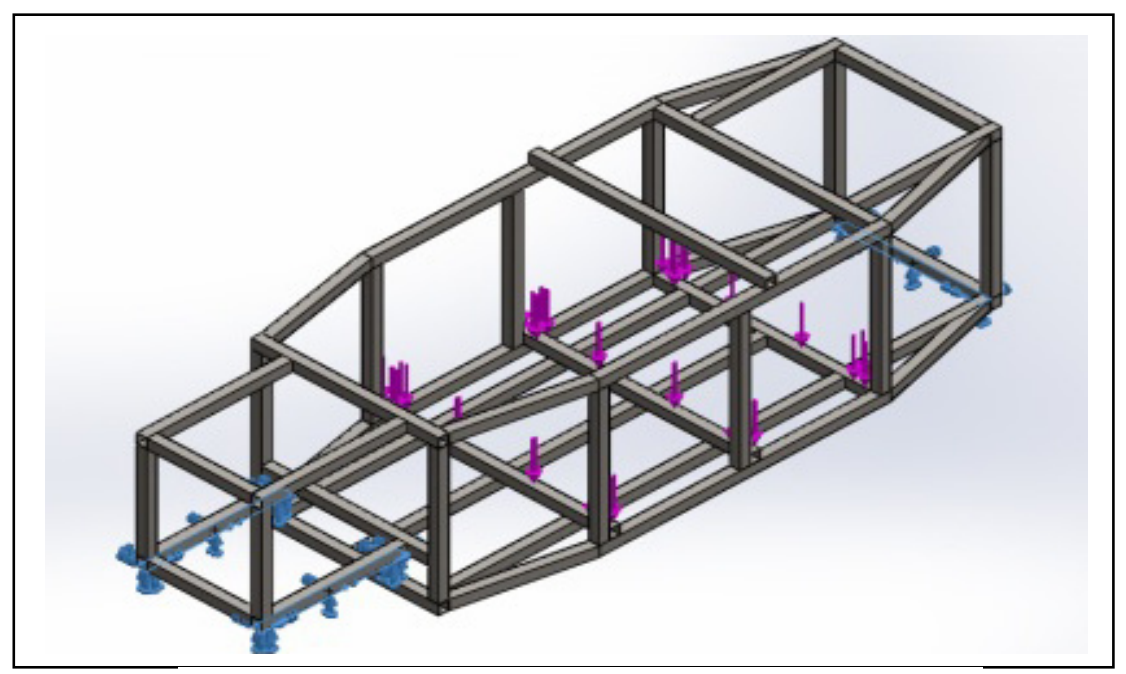

Figure 7. Applied Load View

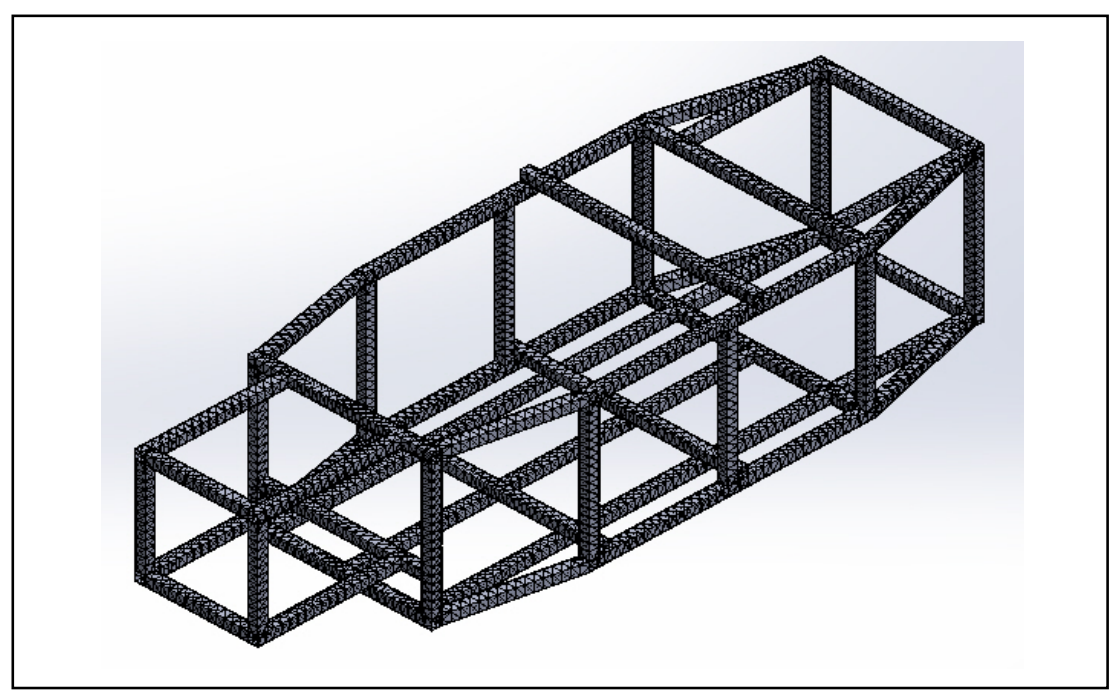

Figure 8. Meshed Structure of the Chassis

Based on the result shown in Figure 9, the Von Mises stress is distributed across the body of the chassis and the yield strength of the structure is at $1.8 \times 10^{8} \mathrm{Nm}^{-2}$. The maximum value of Von Mises stress experienced by the body is $1.7893 \times 10^{8} \mathrm{Nm}^{-2}$ while the minimum value of Von Mises stress is $1387.39 \mathrm{Nm}^{-2}$. From the contour that resemble the magnitude of stress, it is clearly seen that most of the part of the structure having the Von Mises stress from the range $1387.39 \mathrm{Nm}^{-2}$ until $5.9644 \times 10^{7} \mathrm{Nm}^{-2}$. This has shown that the factor of safety of most part of the chassis structure have the minimum value of 3 . This has shown that the chassis structure about to withstand the applied load that we assigned during the test which has the magnitude of $5000 \mathrm{~N}$.

However, the Von Mises stress at the joint of the chassis experience higher stress compared to other part. The joint part of the chassis is the part where we applied the method of welding to form the shape of the structure. The Von Mises stress experienced at the joint part is from the range of $5.9644 \times 10^{7} \mathrm{Nm}^{-2}$ until $1.1929 \times 10^{8} \mathrm{Nm}^{-2}$. At the joint part, the factor of safety has the magnitude of 1.5 which need to be improved. Although the factor of safety is at 1.5 , but it could be more safety to improve the safety factor until it reaches at least 2 to ensure the safety of the users. 


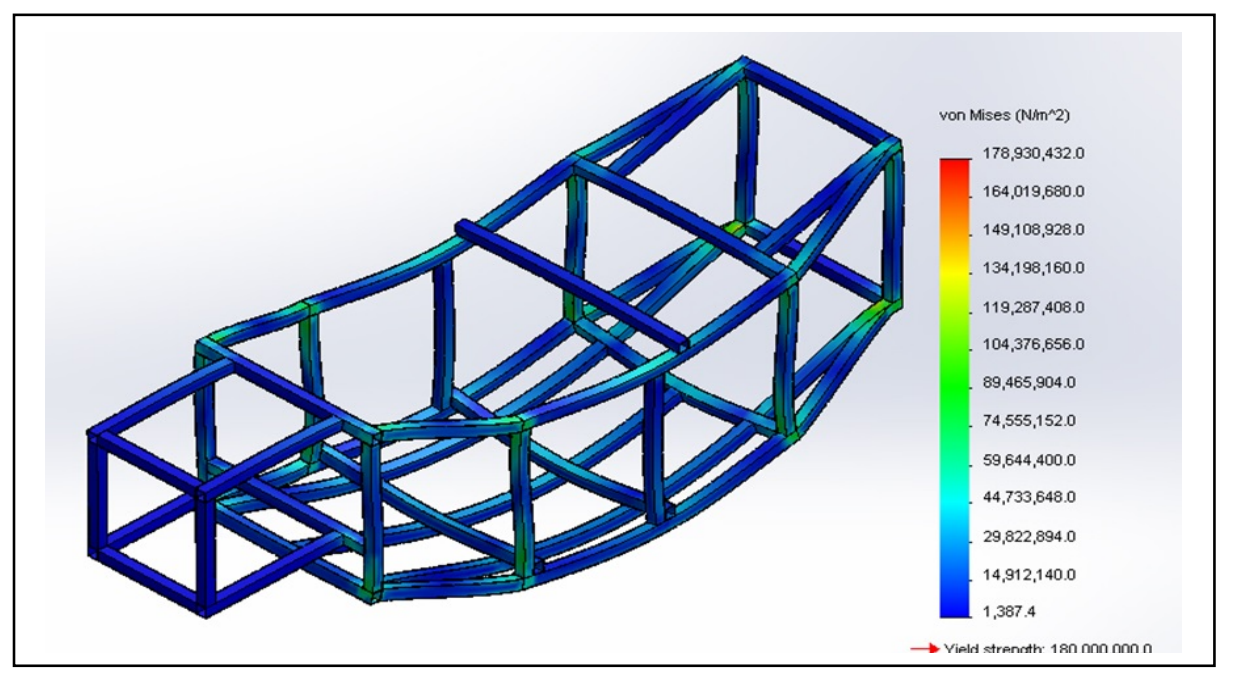

Figure 9. Von Mises Stress Result

The Von Mises stress is highly concentrated at the joint part due to the area of connection between parts. In order to decrease the stress concentration, the area of connection can be increased by using a mounting brackets. By using the mounting brackets in joint connection, not only the stress concentration can be reduced, it can also increase the strength of the structure due to the increasing of connection with the surface of the chassis.

Another figure, Figure 10 depicts the maximum resultant displacement experienced by the chassis structure which has the magnitude of $2.323 \mathrm{~mm}$ while the minimum resultant displacement has the magnitude of $1.0 \times 10^{-30}$ From the contour diagram shown in Figure 10, the front and the rear part near to the fixture experienced the least displacement while the middle part of the chassis where the applied load is located experienced the most resultant displacement.

The resultant displacement of the structure could be significant due to the pressure from the applied load is acting on the supporting square tube is high. Based on the bending of the figure, the structure of the chassis has to be modified to increase the support at the middle part of the chassis to ensure minimum displacement. The uses of rubber mounting or increases the number of supporting tube could be the solution in reducing the resultant displacement. The usage of mounting could absorb some of the pressure exerted during the load applied to the structure. The increases of supporting tube on the chassis structure could allow the applied load to be distributed or divided to other portion of the chassis and reduces the resultant displacement.

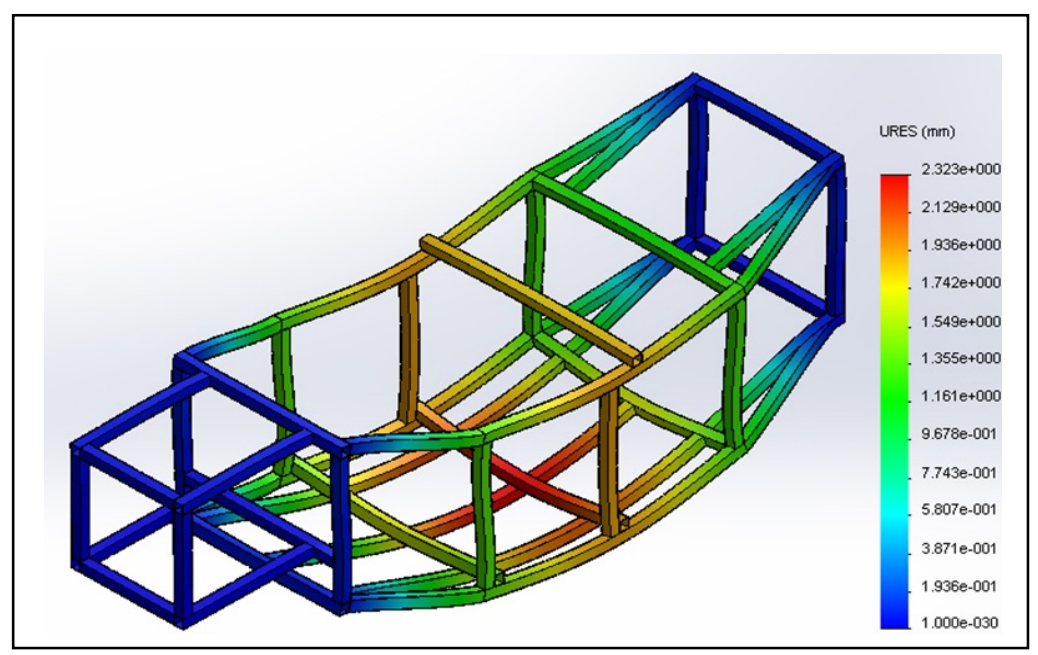

Figure 10. Resultant Displacement 
Figure 11 elucidates the Strain experienced by the chassis structure. The figure shows that the strain distribution on the chassis structure, having the highest strain of $7.038 \times 10^{-4}$ and the lowest strain of $7.679 \times 10^{-9}$. Similar to the Von Mises stress distribution, the strain distribution has the highest concentration at the joint of the chassis structure based on the contour. At the joint of the structure, the strain concentration is at the range from $3.519 \mathrm{x}$ $10^{-4}$ till $7.038 \times 10^{-4}$ which the magnitude need to be taken considerably. The magnitude of strain concentration at that particular location has to be reduced. Besides that, the minimum strain concentration at the range of 7.679 $\times 10^{-9}$ until $1.173 \times 10^{-5}$ on most location of the chassis structure can be considered as low strain concentration.

The higher the strain experienced by the chassis structure determines the easier the structure of the chassis to displace or experience elongation. Strain can be reduced by reducing the stress experienced by the chassis structure since stress and strain are having direct correlation relationship. Therefore, the method of reducing stress can also been applied to reduce the strain experienced by the structure.

Table 2. Specification of Von Mises Stress

\begin{tabular}{cc}
\hline Item & Specification \\
\hline Name & Stress \\
Type & VON: von Mises Stress \\
Min & $1387.38 \mathrm{~N} / \mathrm{m}^{2}$ \\
& Node: 25769 \\
Max & $1.7893 \times 10^{8} \mathrm{~N} / \mathrm{m}^{2}$ \\
& Node: 20979 \\
\hline
\end{tabular}

Table 3. Specification of Static Test Result (Resultant Displacement)

\begin{tabular}{cc}
\hline Item & Specification \\
\hline Name & Displacement \\
Type & URES: Resultant Displacement \\
Min & $0 \mathrm{~mm}$ \\
& Node: 16510 \\
Max & $2.32277 \mathrm{~mm}$ \\
& Node: 9568 \\
\hline
\end{tabular}

Table 4. Specification of Static Test Result (Equivalent Strain)

\begin{tabular}{cc}
\hline Item & Specification \\
\hline Name & Strain \\
Type & ESTRN: Equivalent Strain \\
Min & $7.67918 \times 10^{-}$ \\
& Element: 13271 \\
Max & $7.03849 \times 10^{4}$ \\
& Element: 18371 \\
\hline
\end{tabular}

\section{Conclusion}

This paper has presented a design for a four wheel chassis design which can be occupied or driven by a single driver. The chassis structure selected is the space frame type chassis. Static test is also performed on the chassis design using the simulation function in the Solidworks software. Then, the basic chassis frame structure is fabricated using the materials selected which is the $25 \mathrm{~mm}$ x $25 \mathrm{~mm}$ square mild steel tube with the thickness of $1.6 \mathrm{~mm}$.

The static test conducted using simulation function in Solidwork software determines the Von Mises stress, resultant displacement and equivalent strain experienced by the chassis frame structure. In the static test, the finest available mesh is chosen in order to increase the accuracy of the result obtained. Then, the result obtained are analyzed and discussed. Modification on the chassis frame structure will be done during later to minimize the Von Mises stress, resultant displacement and equivalent strain experienced by the chassis frame.

Based on the result obtained from the static test, the factor of safety (FOS) of the chassis frame structure has the minimum value of 3 at most of the parts, calculated based on the Von Mises Stress contour. However, there are 
also location where the factor of safety (FOS) is less than 2 which located at the joint of the chassis frame structure. Therefore, improvement has to be made on the structure to increase the factor of safety value. While for the resultant displacement result, it can clearly seen that at the middle part of the chassis experienced the most significant displacement which is approximately $2 \mathrm{~mm}$ compared to the front part and the rear part of the chassis frame.

Furthermore, the equivalent strain experienced by the chassis frame structure has the same characteristics as the Von Mises stress contour where the highest strain is concentrated at the joint of the chassis frame. The value of the strain determine and directly affect the displacement of the chassis frame structure.

Finally, the chassis frame developed based on the simulation result obtained from Solidworks software could probably withstand the applied load on the chassis. However, the chassis structure has to be further improved to increase the performance as well as the safety of the chassis.

\section{Acknowledgements}

The author is deeply indebted to the team work at RIA Research Group, Universiti Teknikal Malaysia Melaka for their valuable help and critical guidance. This research work was supported by Universiti Teknikal Malaysia Melaka (UTeM), Malaysia under grant number PJP/2014/FTK(20C)/S01355.

\section{References}

Chignola, S., Gadola, M., Leoni, L., \& Resentera, M. (2002). On The Design Of A Low Cost Racing Car Chassis. International Design Conference - Design 2002, 1035-1040.

Hirsch, J. (2011). Aluminium In Innovative Light-Weight Car Design. Material Transactions, 2(5), 818-824.

Pang, S. Y., Guan, X., \& Zhan, J. (2010). Research Of Chassis Torsional Stiffness On Vehicle Handling Performance. 2010 WASE International Conference On Information Engineering, 253-255.

Rajappan, R., \& Vivekanandhan, M. (2013). Static And Modal Analysis Of Chassis By Using FEA. The International Journal of Engineering (IJES), 2(2), 63-73.

Rajput, Y. S., Sharma, V., Sharma, S., \&Saxena, G. (2013). A Vibration Analysis Of Vehicle Frame. International Journals Of Engineering Research And Application (IJERA), 3(2), 348-350.

Rashid, M. Z. A., Aras, M. S. M., Kassim, A. M., Ibrahim, Z., \& Jamali, A. (2012). Dynamic Mathematical Modeling and Simulation Study of Small Scale Autonomous Hovercraft. International Journal of Advanced Science and Technology, 46, 95-114.

Rashid, M. Z. A., Aras, M. S. M., Radzak, A. A., Kassim, A. M., \& Jamali, A. (2012). Development of Hexapod Robot with Manoeuvrable Wheel, International Journal of Advanced Science and Technology, 49, 119-136. SERC.

Rashid, M. Z. A., Aras, M. S. M., Shah, H. N. M., Lim, W. T., \& Ibrahim, Z. (2012). Design and system parameter's validation of the unicycle mobile robot, 2012 International Conference on Control, Automation and Information Sciences (ICCAIS), 311-316, IEEE.

Reimpell, J., Stoll, H., \& Betzler, J. W. (2001). The Automotive Chassis: Engineering Principles: Chassis And Vehicle Overall, Wheel Suspensions And Types Of Drive Axle Kinematics And Elastokinematics, Steering, Springing, Tyres Construction And Calculation Advice, 2nd ed. USA: Butterworth-Heinemann.

Solasa, G., Saradeep, N. S. D., Prasad, T. R. K., \& Babu, G. S. (2013). Modal Analysis Of Chassis. International Journal of Engineering and Advanced Technology (IJEAT), 2(4), 789-795.

Wang, W. L., Cheng, S. Y., \& Luo, M. J. (2010). Experimental Modal Test For Structure Refinement Of An Automotive Chassis. 2010 International Conference On Measuring Technology And Mechatronics Automation.

\section{Copyrights}

Copyright for this article is retained by the author(s), with first publication rights granted to the journal.

This is an open-access article distributed under the terms and conditions of the Creative Commons Attribution license (http://creativecommons.org/licenses/by/3.0/). 